\title{
Giant retroperitoneal ganglioneuroma
}

\author{
D. Acín-Gándara, A. Carabias, A. Bertomeu, L. Giménez-Alvira, L. Colao and M. Limones \\ Service of General Surgery and Digestive Diseases. Hospital Universitario de Getafe. Madrid, Spain
}

Ganglioneuromas are infrequent neurogenic tumours. They are generally benign and lymphatic or haematogenic metastases are rare. They grow slowly and may secrete hormones. They are usually present in people aged between 10 and 40 years. The most common location is in the posterior mediastinum and the retroperitoneum. They are usually asymptomatic and, when there are symptoms, these depend on the location of the tumour and whether hormones are being secreted or not. Clinically, they tend to be incidental findings that are observed in imaging studies using ultrasonography, computerised tomography or magnetic resonance imaging. Arteriography can be useful to visualise the vascularisation. Blood and urine tests are performed in order to detect hormone secretion. They may also become malignant in the form of a malign Schwannoma. Surgery is the preferred treatment and expected outcome is good if they are completely removed. If this is not the case, then they tend to recur. Post-operative monitoring must be performed in order to rule out local recurrences or new tumour foci (1-4).

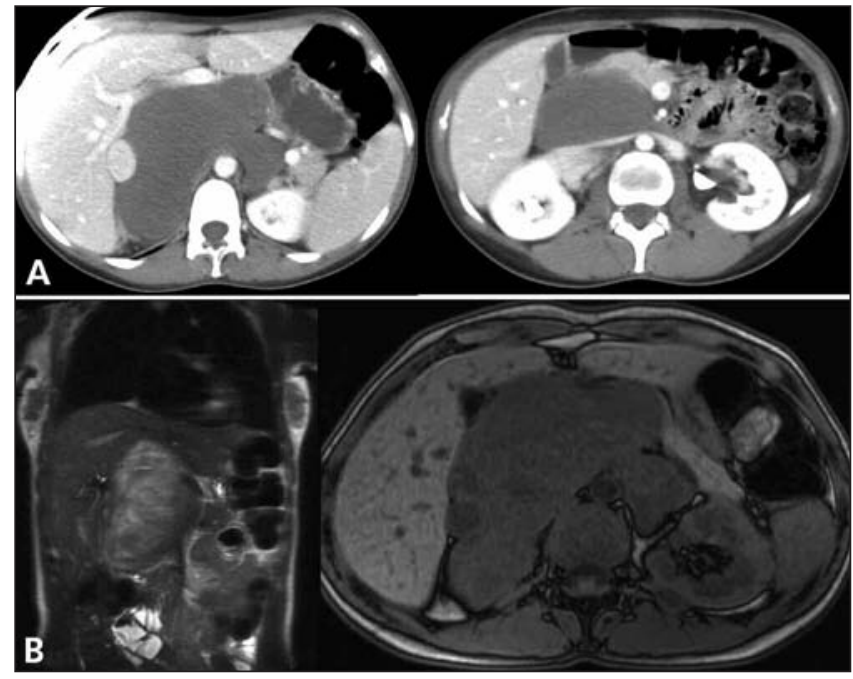

Fig. 1. Large retroperitoneal mass that encompasses the celiac trunk and the superior mesenteric artery. A. Abdominal CT scan. B. MRI. Gran masa retroperitoneal que engloba arteria mesentérica superior y tronco celiaco. A. TC abdominal. B. RM.

\section{CASE REPORT}

We report the case of a 36-year-old female, two weeks pregnant, with mild indirect hyperbilirubinaemia, consistent with Gilbert's syndrome. The patient was asymptomatic, the physical examination was normal and she had high CA 125. Ultrasound imaging, CT scan and MRI of the abdomen revealed a 15-cm heterogeneous retroperitoneal mass that encompassed the celiac trunk and the superior mesenteric artery (Fig. 1), which was consistent with a ganglioneuroma and confirmed by fine needle aspiration biopsy. Monitoring throughout the pregnancy was proposed, but the patient decided interrupt it voluntarily and to undergo surgery.

The procedure used was a midline laparotomy, which showed the presence of a retroperitoneal mass from the left renal vein to the diaphragmatic hiatus, with retrohepatic and retropancreatic involvement, and in close contact with the inferior vena cava and encompassing the celiac trunk and the superior mesenteric artery. The tumour was completely excised by mobilisation of the liver and pancreas (Fig. 2).

\section{REFERENCES}

1. Nelms JK, Diner EK, Lack EE, Patel SV, Ghasemian SR, Verghese M. Retroperitoneal ganglioneuroma encasing the celiac and superior mesenteric arteries. ScientificWorldJournal 2004; 4: 974-7. 


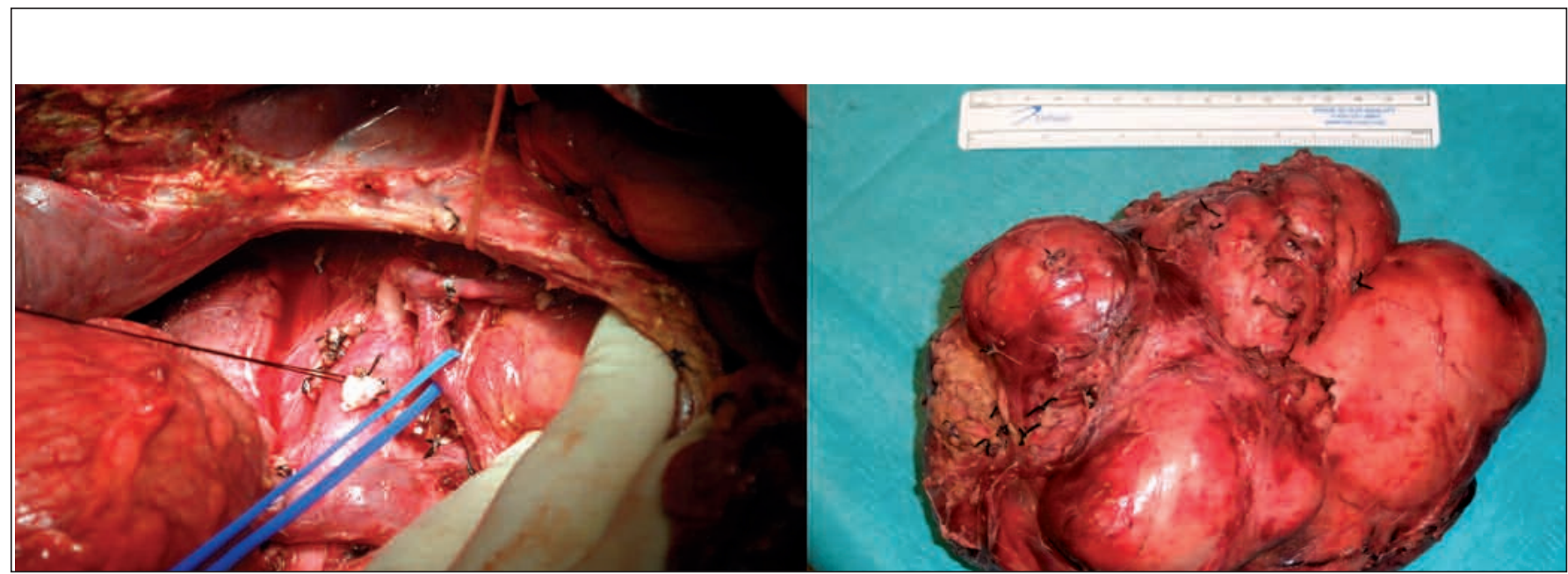

Fig. 2 A. Surgical procedure: partially dissected retroperitoneal tumour, showing the aorta, with the left renal vein crossing it and the celiac trunk dissected. B. Surgical specimen of $18 \times 12 \times 8 \mathrm{~cm}$ and a weight of $935 \mathrm{~g}$. PA: 'Mature' type ganglioneuroma.

A. Intervención quirúrgica: tumoración retroperitoneal parcialmente disecada, observándose la aorta, con la vena renal izquierda cruzándola y el tronco celiaco disecado. B. Pieza quirúrgica de $18 \times 12$ × 8 cm y peso de 935 g. AP: ganglioneuroma tipo "maduro".

2. Fueglistaler P, Gurke L, Stierli P, Obeid T, Koella C, Oertli D, et al. Major vascular resection and prosthetic replacement for retroperitoneal tumors. World J Surg. 2006; 30(7): 1344-9.

3. Yamaguchi K, Hara I, Takeda M, Tanaka K, Yamada Y, Fujisawa M, et al. Two cases of ganglioneuroma. Urology 2006; 67(3): 622-4.

4. Cronin EM, Coffey JC, Herlihy D, Romics L, Aftab F, Keohane C, et al. Massive retroperitoneal ganglioneuroma presenting with small bowel obstruction 18 years following initial diagnosis. Ir J Med Sci 2005; 174(2): 63-6. 